\title{
Investigating and boosting walkability in Sulaimani's mixed-use streets: Jamal Irfan street as a case study
}

\author{
Mariwan Jamal \\ City Planning Engineering \\ Sulaimani Polytechnic University \\ Sulaimani, Kurdistan Region of Iraq \\ mariwanjk.tce27cityplanning@spu.edu.iq
}

\author{
Wanawsha Khasraw \\ City Planning Engineering \\ Sulaimani Polytechnic University \\ Sulaimani, Kurdistan Region of Iraq \\ wanawshakh.tce52cityplanning@spu.edu.iq
}

\author{
Shaey Khabat \\ City Planning Engineering \\ Sulaimani Polytechnic University \\ Sulaimani, Kurdistan Region of Iraq \\ shaeekq.tce42cityplanning@spu.edu.iq
}

\author{
Rozhen K. Mohammed-Amin \\ City Planning Engineering \\ Sulaimani Polytechnic University \\ Sulaimani, Kurdistan Region of Iraq \\ rozhen.mohammed@spu.edu.iq
}

\begin{abstract}
Walkable cities, neighborhoods, and streets promote good health. A growing number of research show compelling evidence about the positive impacts of walkable neighborhoods and streets on everything from real-estate values to health, mental well-being, crime rate, safety feeling, creativity, and even making cities more democratic. Walkability has health, environmental, and economic benefits. For example, several studies found that people in walkable neighborhoods have a higher amount of physical activity and were substantially less likely to be overweight or obese than those living in low-walkable neighborhoods. Walkable neighborhoods and streets incorporate features that promote regular walking, cycling and public transit use. While the city of Sulaimani in general suffers from lack of walkable neighborhoods and streets, due to many factors including incomplete streets, some of the city's neighborhoods and streets have potential for becoming effective walkable neighborhoods and streets. The recent mixed use developments and re-developments in some of the areas and streets in the city have attracted a large number of people and increased the necessity of making those areas and streets more pedestrianfriendly and walkable. This research aims at investigating walkability characters in Sulaimani city's recently developed mixed-use streets through closely examining a representing case study, Jamal Irfan street. The research then proposes strategies, guidelines, and urban design interventions that make those streets more pedestrian friendly according to urban design standards.
\end{abstract}

Keywords: Walkability, pedestrian friendliness, physical activity, safety, neighborhood and public space quality, urban design and planning.

\section{BACKGROUND}

Walking is the first and simplest type of moving for most people that is performed for both transportation and leisure purposes. Although it does not need special equipment or facilities, it does require a supportive environment [1]. Walkability reflects "overall walking conditions in an area" [2]. Walkability is "a multifaceted measure of how friendly an area is to walking"; It extends beyond "ability to walk" that requires good enough street crossings and sidewalk designs to take into consideration diversified physical, social, and psychological factors that affect people's walking behaviors such as the quality of the built environment, pedestrian facilities, buildings' spatial configuration and functions, enjoyment, and safety perception [3]. Different urban levels impose their requirements on walkability. For example, at a neighborhood or street level, walkability is affected by the availability and quality of sidewalks and crosswalks, roadway conditions (such as road width and traffic speeds and volumes), while on the community level it is also affected by "land use Accessibility, such as the relative location of common destinations and the quality of connections between them" [3].

For many centuries, walkability was at the center of urban designers and city planners' attention who have been advocating for the creation of urban forms and activities that supports walking [1]. Yet, modern cities with their automobile oriented designs and planning policies have negatively affected the quantity and quality of people's walking, and therefore, daily physical activity. In modern cities, we can see neighborhoods without sidewalks, public spaces made redundant by parked vehicles, and urban highways that separate neighborhoods to serve sprawling suburbs [3]. In addition to health and well-being concerns, lack of walking-friendly neighborhoods and streets that offer car-centric lifestyles have significant negative environmental, economic, and social impacts on cities and urban areas.

Although urban design and planning pioneers like Lewis Mumford, Jane Jacobs, William H. Whyte, and Jan Gehl started to question the effect of automobile dependency on the quality of urban forms and decline in humanfocused approach to urban planning and developments, realization about the positive role of walkability in urban environments is a recent phenomenon [3].

Like many around the world, the city of Sulaimani has become heavily dependent on cars and less walkable over time. The city is experiencing massive traffic congestion and road accidents in addition to the subsequent economic and environmental impacts from its car dominance planning policies. Private cars dominate movements and spaces even in public spaces such as parks and mixed-used streets with good opportunities to walk. Lack of walking supportive planning and traffic policies and guidelines are aggravating the condition and limiting safe and convenient walking opportunities for pedestrians. Fatal 
car accidents and premature deaths are on the rise within and outside the neighborhoods. With the continuous transformation of some of the neighborhood streets into mixed-use streets with various shops, cafés, and restaurants, which have brought night-life, pedestrians, and cars simultaneously, the urgency of making these streets safely walkable for pedestrians is becoming high. Our study investigates a highly popular street with its recent transformation into a dense mixed-used street, Jamal Irfan in Bakhtyary neighborhood. By analyzing the street's physical components, spatial configuration, and usability, we aim at investigating its walkability characters and, accordingly, propose strategies and urban design solutions and guidelines to improve walkability in the street, which can lead to an increase in the residents and visitors' physical activities and well-being. We believe that re-developing Jamal Irfan into a successful walkable street can serve as a good model for other streets to follow in the city and the region.

\section{WHY WALKABILITY IS IMPORTANT?}

Walkability is an important asset for any environment (natural or built); It improves urban experience and along this it offers many benefits, including social, health, economic, environmental, and even political.

\subsection{Social benefits}

Walkability has a number of direct and indirect social benefits. It enables experiencing urban environments at the human scale [3]. It also increases the movement and stay of people in public realms and, therefore, intensifies public space uses [3]. This lead to an increase in social interaction and activities among people [4], which is an essential feature in the built environment.

Walkability enhances community livability and sense of place [5]. It has become an indicator of community's livability since it can play a key role in attracting workers, businesses, and tourism [6]. Walkable communities have higher sense of community, which is fundamental to develop social network and support to the community members. Findings from a study suggest that residents of walkable neighborhoods have over $80 \%$ higher levels of social capital than the residents of the car dependent neighborhoods [4]. Research shows that walkable streets and communities attract higher number of people to live and visit, and improve safety perception [6] [7]. Low perception of safety in a community can discourage people from walking. Some cities and communities use walkability as a strategy to reduce crimes [8] [9].

Furthermore, walkability promotes integration among community members from different genders, age groups, physical abilities, and background. It increases accessibility of public spaces and communities for people with different mobility levels and background [3]. In doing so, increases diversity and attractiveness of a street or community. Walkability is also recognized as a driver for creativity. Walkable streets and spaces support the development of art and culture and appeal to performers and artists who can enliven the streets and spaces for further attracting and engaging people [3].

\subsection{Health benefits}

Walkability has great physical and mental health benefits. Walking promotes active living and physical activity, which can increase health risks resilience and reduce blood pressure, improve blood cholesterol levels, and lower body mass index [10]. Active living is associated with longevity. Older people, aging over 60, who exercise (such as walking) just 15 minutes a day reduce risk of early death by $22 \%$ [10].

Physical inactivity, such as from car dependency combined with little exercises and walking, is considered a main cause of most chronic diseases. Doctors started to prescribe 30 minutes of physical activity every day to enhance physical health and longevity [11]. Walkable environments increase people's motivation to walk for daily activities and enjoyment and, therefore, help them achieve their daily recommended amount of physical activity. Investing in walkability not only helps improving people's life style, but also saves costs spent on health care.

The mental health and well-being benefits of walking is no less than those of physical health. A study concluded that people who walk over 8.6 minutes a day are more likely to report a better mental health [4]. Walking improves cognitive performance [12]. It also positively affects people's mood and mental health from decreasing the risk of stress, anxiety, and depression [3]. Walking increases producing endorphins that counteract stress and lower cortisol levels, which can lead to improving sleep, reducing symptoms of mild depression, and increasing of self-confidence [3]. Walking is linked to happiness and higher life satisfaction. A University of Zurich study found that "a person with a one-hour commute to work has to earn $40 \%$ more money to be as satisfied as someone who walks" [13] [14].

\subsection{Economic benefits}

The economic benefits of walking have been described as "the walking economy". Major cities like Melbourne in Australia observes a direct association between the "city's economic prosperity and the safety and convenience of the pedestrian experience" [15]. In addition to improving health, walkable environments also increase wealth; It raises spending at local retails, enhances value of local goods and services, and creates job opportunities [3]. A recent study suggests that improving walkability can increase shopping and trading by up to $40 \%$ [3]. By comparing retail activity, using sales tax receipts, before and after redesigns of an underused parking area in a pedestrian plaza in Brooklyn, the Transportation Department of the New York City found a significant increase of $172 \%$ in retail sales [3]. 
In addition to supporting local businesses, an increase in walking enhances long-term cognitive function, productivity, decision making, and creative thinking [16]. These can have positive economic consequents. Between 20102015 many American companies have either relocated, opened new offices, or expanded in walkable downtowns as they realized that these walkable areas support creativity among their employees [17]. Walkability makes neighborhoods and cities attractive not only for businesses but also people (including tourists). Many tourists find walking the best way to experience a city because it improves the "image ability" of a place, which makes the city more memorable and recognizable [3]. Walking has become an effective tool for promoting cities and attracting tourists. Walkable environments have less vacancies and, therefore, more thriving public spaces.

\subsection{Environmental benefits}

Walking is an inclusive sustainable mode of transport at no cost [18]. Sustainable development encourages less car and more walking. Walkable and pedestrian-oriented environments have more compact infrastructures than car-oriented environments. Fewer materials and smaller constructions are used in pedestrian-friendly environments and cities. In this regard, walkable environments have lower environmental footprint. Walkability can help mitigating the negative environmental impact from car dependency and caroriented developments such as greenhouse gas emission and air pollutions [3].

Walkability can significantly reduce energy consumption. In his "The Walkable City" TED talk Jeff Speck (2013) argues that changing all light bulbs to "energy-savers saves as much energy in a year as moving to a walkable city does in a week" [19]. Christensen (2014) verified Speck's claim by calculating and comparing saving from average household lighting consumption (when energy-saving lightbulbs are used) to average household gasoline consumption (when private car use is reduced by $95 \%$ ) [20].

\section{CRITERIA AND PRINCIPLES FOR WALKABLE ENVIRONMENTS}

Urban design pioneers like Jan Gehl believe that it takes more than just a good paving to create a good walkable environment [21]. It is the combination of physical environment with people and their senses and perceptions that make a street or space pedestrian friendly. Criteria and principles for producing walkable environments, therefore, include both physical standards as well as criteria and principles that consider human senses [21].
Ghel (2006) summarized these principles and criteria in

\begin{tabular}{|c|c|c|c|}
\hline $\begin{array}{l}\text { P } \\
\text { R } \\
\text { O } \\
\text { T } \\
\text { E } \\
\text { C } \\
T \\
\text { I } \\
\text { O } \\
\text { N }\end{array}$ & $\begin{array}{l}\text { 1. Protection against } \\
\text { Traffic \& Accidents } \\
\text {-traffic accident } \\
\text {-fear traffic } \\
\text {-other accidents }\end{array}$ & 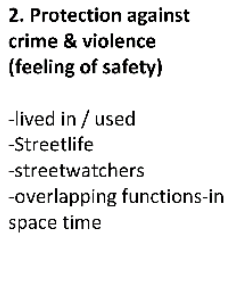 & $\begin{array}{l}\text { 3. Protection against } \\
\text { unpleasant sense } \\
\text { experiences } \\
\text {-wind/draft } \\
\text {-rain/snow } \\
\text {-pollution } \\
\text {-dust, glare, noise }\end{array}$ \\
\hline $\begin{array}{l}C \\
0 \\
M \\
F \\
O \\
R \\
T\end{array}$ & $\begin{array}{l}\text { 4. Possibilities for } \\
\text { WALKING } \\
\text {-room for walking } \\
\text {-untiering layout of street } \\
\text {-interesting facades } \\
\text {-no obstacles } \\
\text {-good surfaces }\end{array}$ & $\begin{array}{l}\text { 5. Possibilities for } \\
\text { STANDING/STAYING } \\
\text {-attractive edges } \\
\text { (Edge effect) } \\
\text {-defined spots for staying } \\
\text {-supports for staying }\end{array}$ & $\begin{array}{l}\text { 6. Possibilities for } \\
\text { SETTING } \\
\text {-zones for sitting } \\
\text {-maximizing advantages } \\
\text { primary and secondary } \\
\text {-sitting possibilities } \\
\text {-benches for resting }\end{array}$ \\
\hline & $\begin{array}{l}\text { 7. Possibilities to SEE } \\
\text {-seeing-distance } \\
\text {-unhindered views } \\
\text {-lighting (when dark) }\end{array}$ & $\begin{array}{l}\text { 8. Possibilities for } \\
\text { HEARING /TALKING } \\
\text {-low noise level } \\
\text {-bench arrangement } \\
\text { talks capes }\end{array}$ & $\begin{array}{l}\text { 9. Possibilities for } \\
\text { PLAY /UNFORDING/ } \\
\text { ACTIVITIES } \\
\text {-invitation to physical } \\
\text { activities, play, unfolding } \\
\text { \& entertainment - day \& } \\
\text { night and summer \& } \\
\text { winter }\end{array}$ \\
\hline $\begin{array}{l}E \\
N \\
J \\
O \\
Y \\
M \\
E \\
N \\
T\end{array}$ & $\begin{array}{l}\text { 10. Scale } \\
\text {-Dimensions of buildings } \\
\& \text { spaces in observance of } \\
\text { the important human } \\
\text { dimensions related to } \\
\text { senses, movements, size } \\
\text { \&behavior }\end{array}$ & $\begin{array}{l}\text { 11.Possibilities for enjoying } \\
\text { Positive aspects of climate } \\
\text {-sun/shade } \\
\text {-warmth/coolness } \\
\text {-breeze/ventilation }\end{array}$ & $\begin{array}{l}\text { 12. Aesthetic } \\
\text { quality/positive sense - } \\
\text { experiences } \\
\text {-good design\& good } \\
\text { detailing } \\
\text {-views/vistas } \\
\text {-trees, plants, water }\end{array}$ \\
\hline
\end{tabular}

three categories: protection, comfort, and enjoyment [22]. Each of these main principles include a set of principles and criteria (see Figure 1).

Figure 1. Jan Ghel's criteria categorization to achieve walkability [21].

\subsection{Protection}

A street or environment cannot become walkable if they do not have the primary human need, safety and protection. A street must provide conditions that protect pedestrians from traffics, accidents, crimes, unpleasant climate conditions such as wind and pollution, and any other condition that compromise their safety feeling. Research suggest that safety considerations play an important role in people's decisions about the type of transportation they use [23]. People are less likely to walk if they do not feel safe and protected [24].

Protection focuses on minimizing safety and protection related risks. Streets must, therefore, have basic pedestrian infrastructure such as sidewalks, safe street crossings, and other elements that provide protection and safety to the pedestrians. There is a significantly higher 
likelihood for pedestrian crashes in streets without sidewalks (more than twice) than those with sidewalks on both sides [25]. Furthermore, $45 \%$ of pedestrian fatalities happen where no crosswalk is available [26]. Availability of sidewalks not only increase walking, but also improve health as people get their recommended daily amount of physical activity and are in less risk for obesity [27].

Walking become less welcoming and feel less safe (or even more dangerous) in public spaces that are dimly lit, secluded, and poorly maintained and have narrow sidewalks and unmarked streets [28]. People tend to feel safer when they walk in well illuminated environments visible from homes [29]. Urban designers use buffers between pedestrian and vehicle traffic in pedestrianfriendly streets such as bicycle lanes, car parking areas, trees and other landscaping elements [23]. Traffic calming and speed reducing through measures such as speed limit signs and speed humps are two other strategies for increasing safety and reducing rates of accidents, injuries, and even death [23]. Faster moving vehicles cause a higher number and more fatal crashes with pedestrians (see Figure 2).

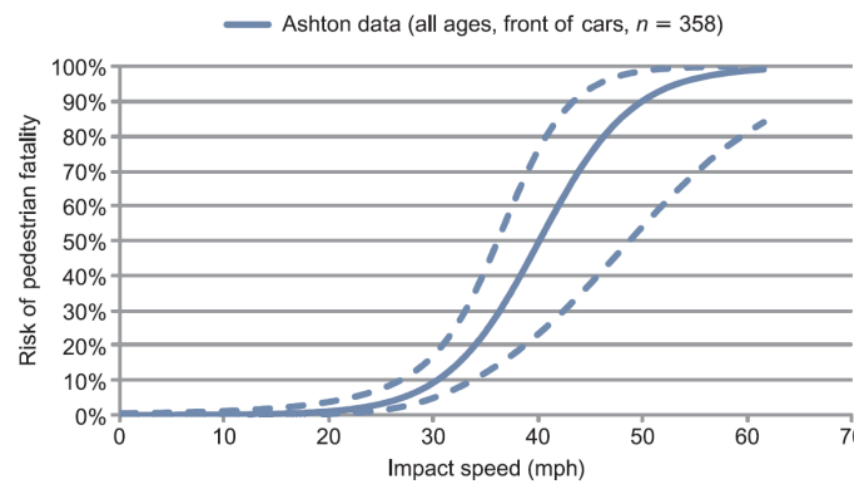

Figure 2. A pedestrian's chance to die from being hit by a car with different speed [30].

\subsection{Comfort}

A pedestrian supporting street should be comfort and convenience. Comfort refers to "the quality of walking and staying in a place"; It involves "walking, standing and sitting as well as the possibility for seeing, hearing and talking" and even playing, and unwinding [21]. In contrast to car riders, pedestrians' physical and mental comforts highly rely on the environment and facilities around them. On a hot day, pedestrians supporting streets need to be shaded and offer places for sitting and resting. Misleading signs and illegible environments frustrate pedestrians [23]. Direct access to building entrances, short blocks, frequent street crossings, easy access to public transportation, convenient seating and benches, water fountains, shade trees all make a street or public space more comfort for walking [23]. A comfort walking environment facilitates basic human activities under good conditions and offers "opportunities to participate in a variety of activities and experience the surroundings" [21].

\subsection{Enjoyment}

Enjoyment covers the human scale, "enjoying the positive aspects of the climate and the sensory experience of the place, including design and the quality of materials used" [21]. Making streets and public spaces enjoyable helps with not only making those places attractive for walking, but also for staying. In this regard, they make those places destinations and not just throughtraffic [22].

To create enjoyable walkable spaces, it is essential to utilize quality, attractions, and special opportunities around the spaces [21]. Walkable environments should offer a variety of activities and destinations for pedestrians, and have "good quality space nearby for them to stop, relax and enjoy the life around them" [22]. Encouraging mixed use developments along improving public transportation is one of the strategies used by urban designers for making a street or public space enjoyable for pedestrians. Emphasizing human scale with fine details and good finishing and street furniture also make a space enjoyable for walking and remaining [21]. Furthermore, environments that offer good experiences, nice views, and interesting sensory impressions make walking more enjoyable.

\section{RESEARCH METHODOLOGY}

To achieve the research objectives, we took Jamal Irfan street as a case study for a major mixed-use street in Sulaimani. By analyzing the street's physical components, spatial configuration, and usability we aim at determining the street's walkability characters and degree of pedestrian friendliness. For the analysis, we collected different data types and through different sources and methods such as satellite maps, interviews with experts, decision makers, and stakeholders, official field surveys and observations, and pedestrian questionnaire. By synthesizing the knowledge from the literature with the specific context of Jamal Irfan street, we then propose urban design and planning solutions and guidelines to improve walkability in the street. Given the similarity in the context, this street can serve as an example to similar streets in the city of Sulaimani and the region. Therefore, some of the findings from the investigations and the recommendations for redeveloping the street to a pedestrian friendly mixed-used street can, to some extent, be generalized and transferred to other streets in the city and similar context in the region. 


\section{CASE STUDY: JAMAL IRFAN STREET}

Like many other streets in the city of Sulaimani, Jamal Irfan street has recently evolved from a residential dominant street into a mixed-use street. The location and potentials of street, supported by the economic growth of the city until 2013, has accelerated its rapid transformation into a vibrant and popular mixed-use street. The street is located in Bakhtairy neighborhood which is, for most, a middle class neighborhood. The street is now a hub for shopping, eating, and enjoyment, especially in evening and night times. It attracts both

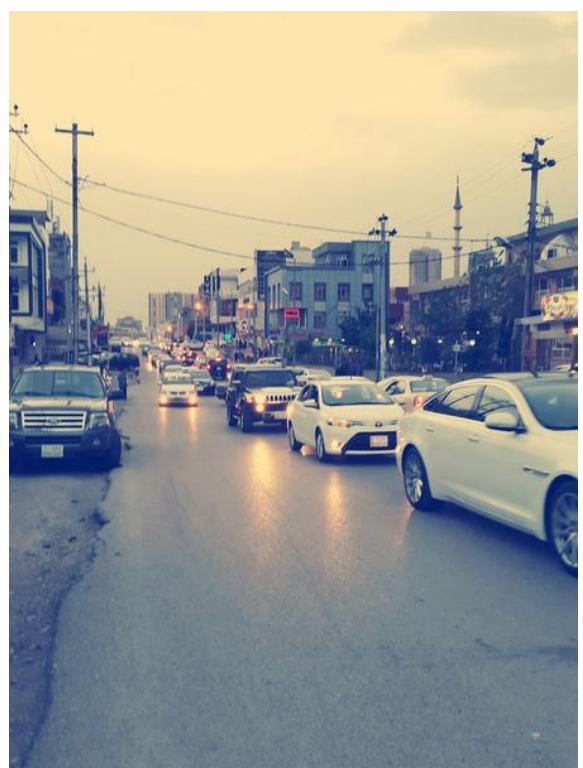

pedestrian and drivers from different age groups and backgrounds. The locals call Jamal Irfan an "Show off street" due to its frequent use for cruising, driving as social and recreational activities, by young drivers, often with expensive cars (especially after sunset). This use often leads to traffic congestion in evening and nighttimes.
Figure 3. A view from Jamal Irfan street at sunset

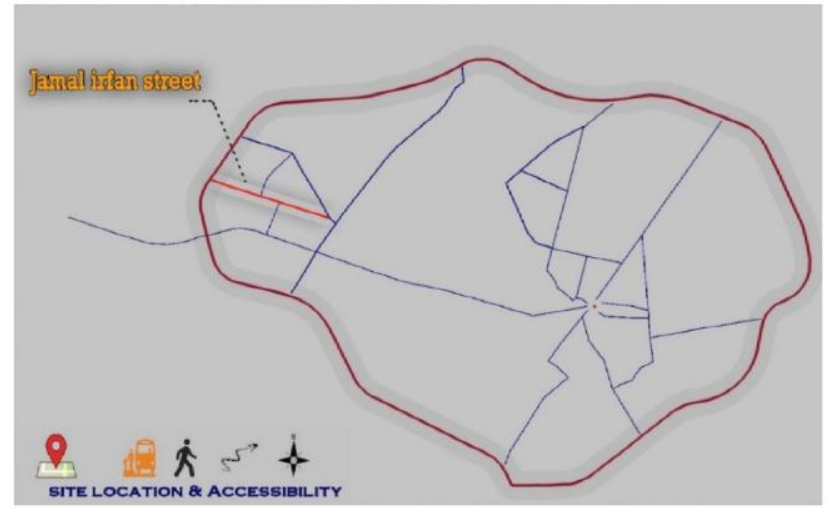

(Photo credit: Danyar Bakr).

Despite its popularity, the street is far from being considered a walking friendly street by urban design criteria. The increasing number of commercial, social, and recreational activities on the street with the growing number of pedestrians, including families with children are increasing risks of pedestrian and car crash injuries and death. Fatal accidents and crashes have occurred in this and other similar streets such as Piramagrun (previously called Shekh Farid) street. As a result, the necessity of re-designing the street has become a necessity.

\subsection{Site analysis}

The strategic location of Jamal Irfan street connects it to three main streets of the city (Media, Salm, and Malik Mahmood streets). The street, therefore, has a good connection and direct access to the rest of the city (see Figure 4 and 5). The street includes and is surrounded by a number of city-scale landmarks, including a mosque, popular mall, art and youth centers, and a 5-star hotel (see Figure 6).

Figure 4. The location of Jamal Irfan street according to the city.

Figure 5. Sun and wind directions in relation to Jamal Irfan street.

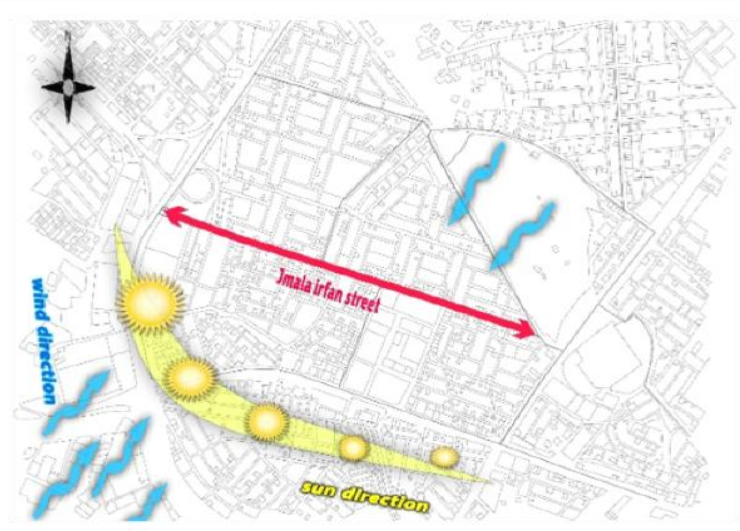


This street is about $1.47 \mathrm{~km}$ long and a width of $30 \mathrm{~m}$ (according to the municipality master plan). However, the existing width on the ground differ due to violating municipality's setback regulations and bylaws by some of the buildings on the street. As a result, the street width currently ranges between 18,25 , and $20 \mathrm{~m}$. New bylaws for any re-development or new construction on the street enforce a setback of $5 \mathrm{~m}$ from the street through

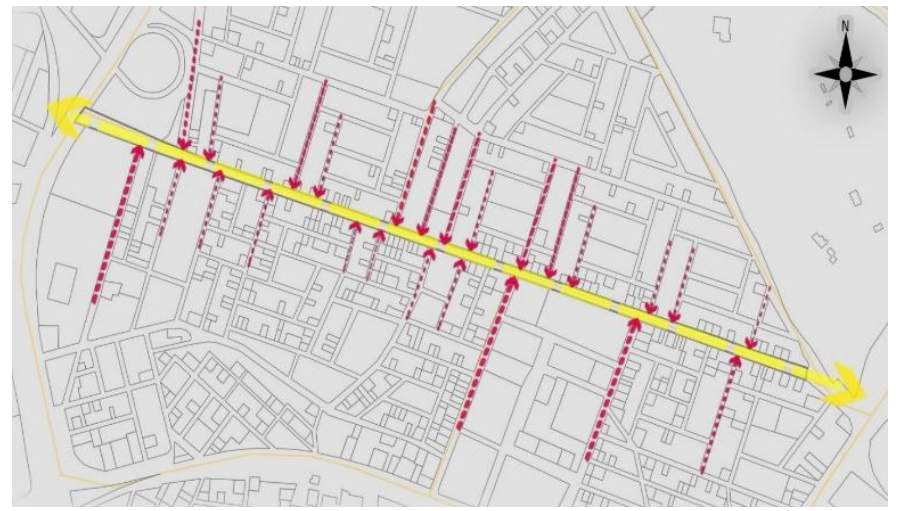

restricting building permissions. The land use of the Bakhtairy neighborhood illustrates the evolution of the street from a residential to a mixed-used street (see Figure 6). The new functions include a wide range of

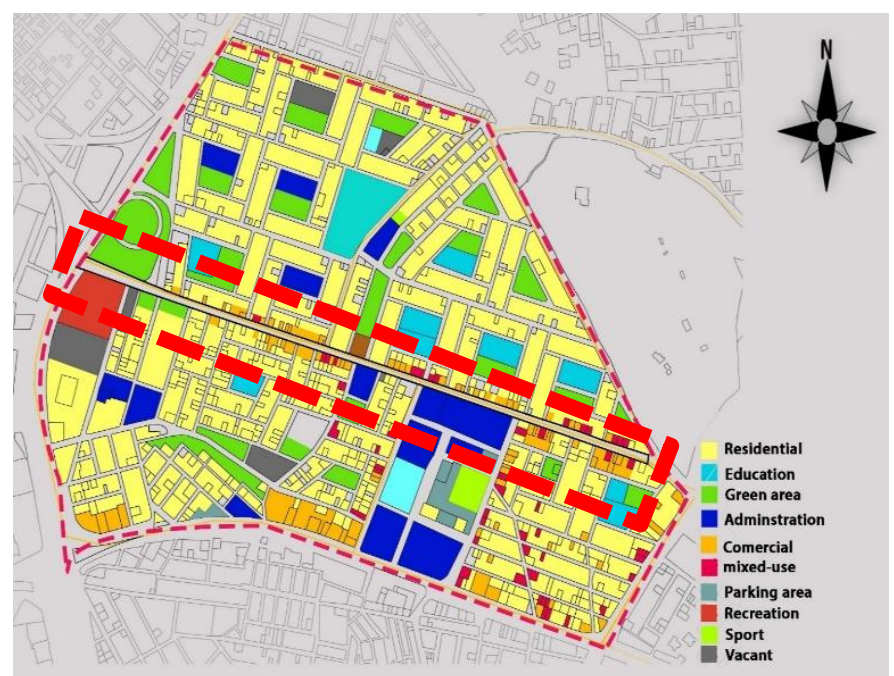

activities such as clothing and shoe shopping, café and restaurants, convenient stores, grocery and butchery shops, pharmacy, and printing and stationary shops. Currently, only $28 \%$ of the buildings located on Jamal Irfan street are residential houses. The building heights on the street ranges between one to four floors.

Figure 5. Land uses around Jamal Irfan street and in Bakhtairy neighborhood.
The street has a total of $21 \mathrm{~T}$ and two 2-lane street intersections, creating short blocks and crossing distances (see Figure 6). There are eight U-turns on the street that negatively affects traffic on the street.

Figure 6. Intersections on Jamal Irfan street.

\subsection{Physical challenges}

The street has a number of physical challenges that compromise protection, comfort, and enjoyment principles of pedestrian friendly streets. The followings are some of the main challenges.

\subsubsection{Uneven and inconsistent sidewalks}

The sidewalks of the street are uneven in terms of height (ranging from zero to $50 \mathrm{~cm}$ ) and alignment with the street and inconsistent in relation to width (ranging from 1.5 to $8 \mathrm{~m}$ ) and materials (see Figure 7 and 8 ). In addition to negative effects on safety and comfort of walking, lack of continuity in the sidewalks are negatively affecting the pedestrian's enjoyment experience. Some of the businesses has monopolized the sidewalks as sitting areas due to weak bylaw enforcement. As a result, some pedestrians are forced to walk on the street in those areas.
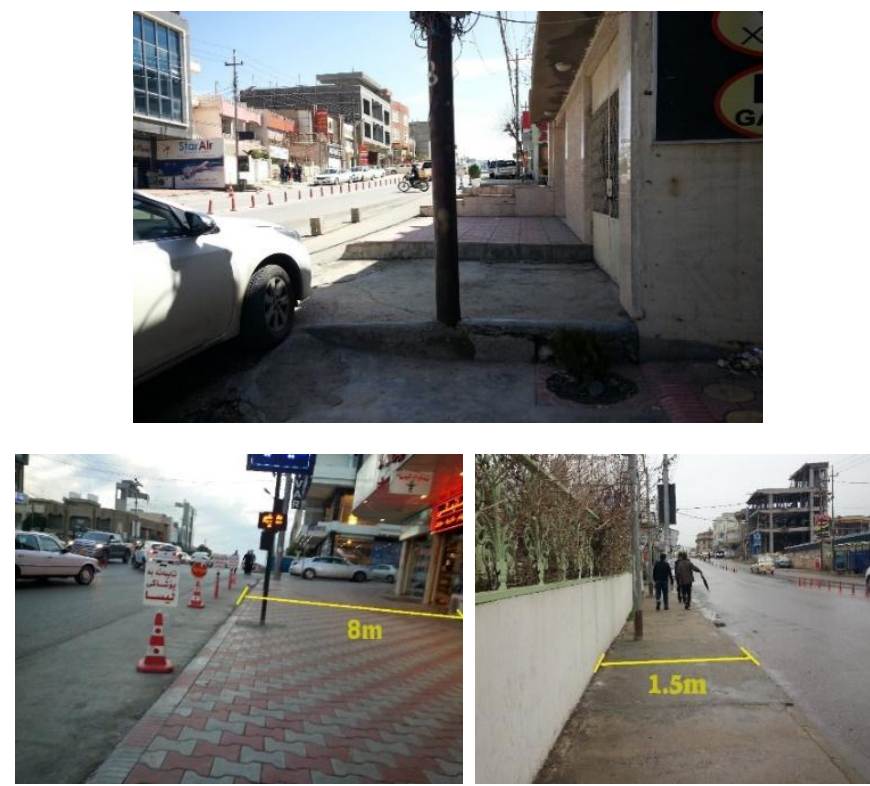

Figure 7. An uneven sidewalk heights (top) and a large variation in sidewalk width (bottom). 


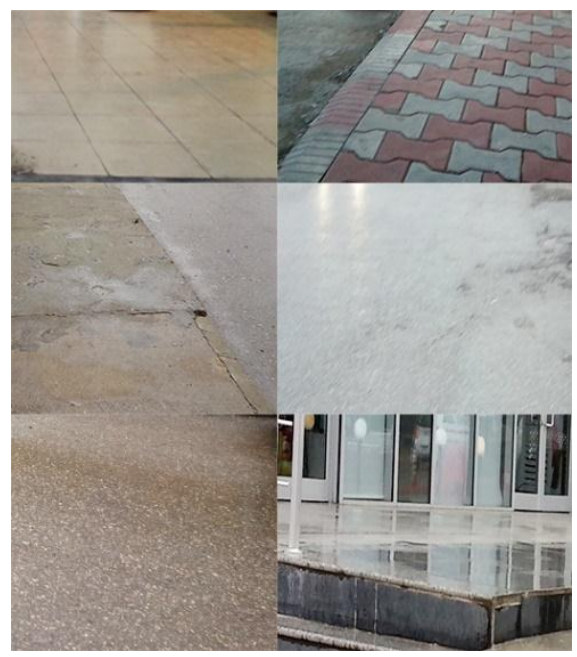

Figure 8. A large variation in sidewalk materials and height.

\subsubsection{Low quality edges, corners, finishing, and maintenance}

The streets edges (including building facades), corners, and finishing are mostly in low quality. In addition to decreasing the visual quality of the street, these negatively affect the pedestrians' perception and enjoyment of the street. The irregular buildings setbacks

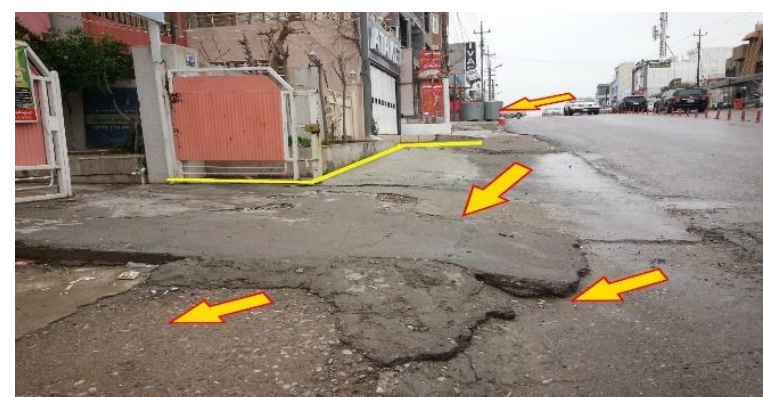

decrease the street's continuity and enclosure, two good urban design principle. Some of the corners are not welldefined and poorly developed, which make the corners illegible for pedestrians. The buildings and surface finishing are in low quality and are poorly maintained. An increasing body of literature associate poor maintenance with higher risk perception. Good maintenance is essential in maintaining low risk perception about an area or street [31].

Figure 9. Irregular street edge and poor quality surface finishing and maintenance.

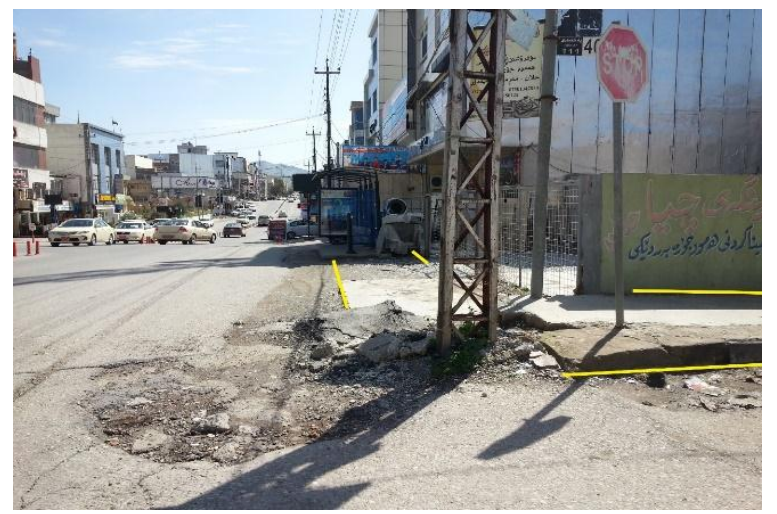

Figure 10. Illegible corners.

\subsubsection{Poor elements design and configuration}

Many of the buildings elements (such entrance and as stairs), sidewalks, and ramps on the street are poorly designed and configured. In addition to visual experience of the street from, sometimes these compromise the safety and comfort of when using the street and its facilities. Lack of strict urban design guidelines and regulations as well as loose municipality bylaws enforcement are contributing to poor design and configuration of the street elements. There are no walking facilities for people with disabilities.

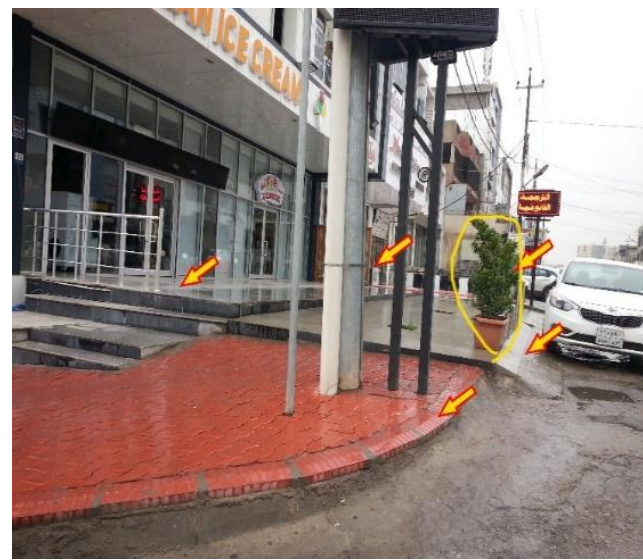

Figu

re 11. Poor building entrance design and building and landscape elements configurations.

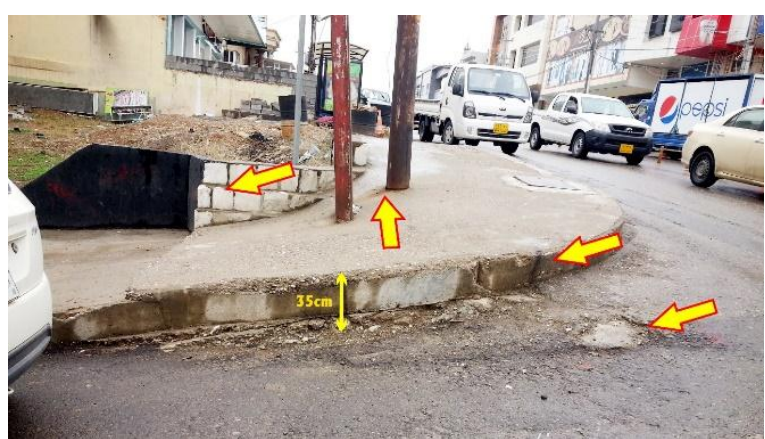

Figure 12. Poor sidewalk slope design and power poles configuration. 


\subsubsection{Insufficient street and landscape furniture}

There is an inadequate number of street furniture such as lighting poles, benches, garbage bins, and traffic and directional signs. Many sections of the street are dimly lit at night (see Figure 13). There are no public resting places for pedestrians on the sidewalks, except for the private sitting areas of some of the cafe shops and restaurants. Lack and location of the few garbage bin result in littering. Lack of adequate traffic signs and marking, including speed sign, sometime lead to traffic congestion and an unsafe mix of vehicle and pedestrian movements, especially at the intersections and crossing areas. Cars park on the street without any parking regulations. All these affect the pedestrian's real and perceived safety while walking and staying. It is worth noting that, despite its popularity, the street lacks reliable public transportation, which is essential for an inclusive accessibility to the street and reducing the use of private cars.

There is a vast variation among the business' advertising board size and location, which compromise the look and feel of the street. There is limited number of greenery and landscape furniture and those that exist are in poor condition or are poorly distributed. There is a total of 11 randomly distributed trees on the street that can offer shade to the pedestrians during the city's hot summer season. Some newly developed sidewalks include

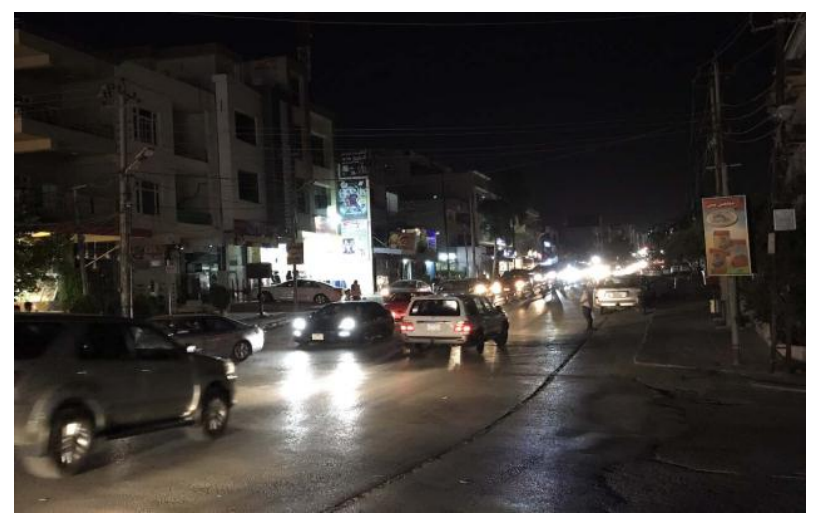

dedicated spots for greenery and trees, however, nothing has been planted.

Figure 13. Poor lighting condition of some parts of the street.

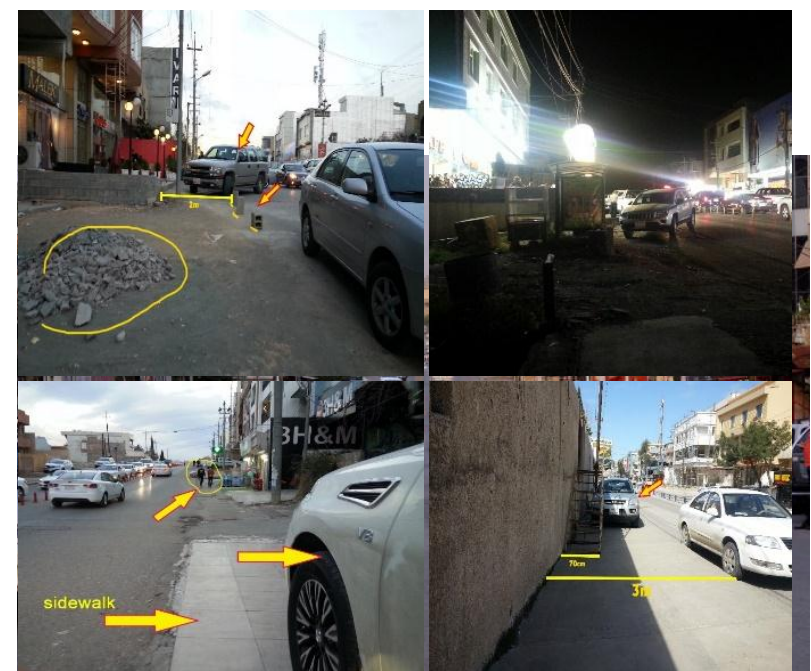

Figure 14. Lack of adequate traffic and directional signs on the street.

Figure 15. Cars parking randomly on the street and even sidewalks from lack of parking regulations and enforcement.

Figure 16. Unorganized street and landscape furniture on the street.

\subsection{Usability challenges}

The street pedestrian ranges from different age groups, gender, and background. We observed a high number of children presence, possibly to due to the family-oriented nature of some of the activities and shopping on the street. We also noticed that the street serve as a gathering point for some informal workers.

We observed that the physical challenges had negatively

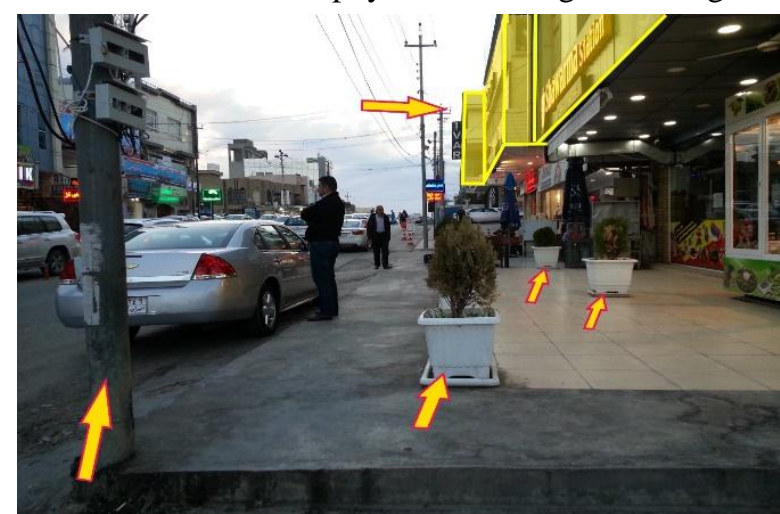

affected the usability of the street and some pedestrians' safety and enjoyment perception. In a survey with 30 adult pedestrians and local people, we found that a high majority of $63 \%$ (19 participants) feel unsafe or very unsafe (see Figure 17). Despite these perceptions, interestingly, the majority of the respondents (57\%) reported that they find walking in the street interesting or very interesting (see Figure 18). While lack of safety awareness and low safety and comfort threshold play a role, these responses show that the street has great potentials and opportunities to become an inclusive, safe, comfort, and enjoyable street for walking.

Figure 17. Participants response distribution to feeling safe when walking in Jamal Irfan street.

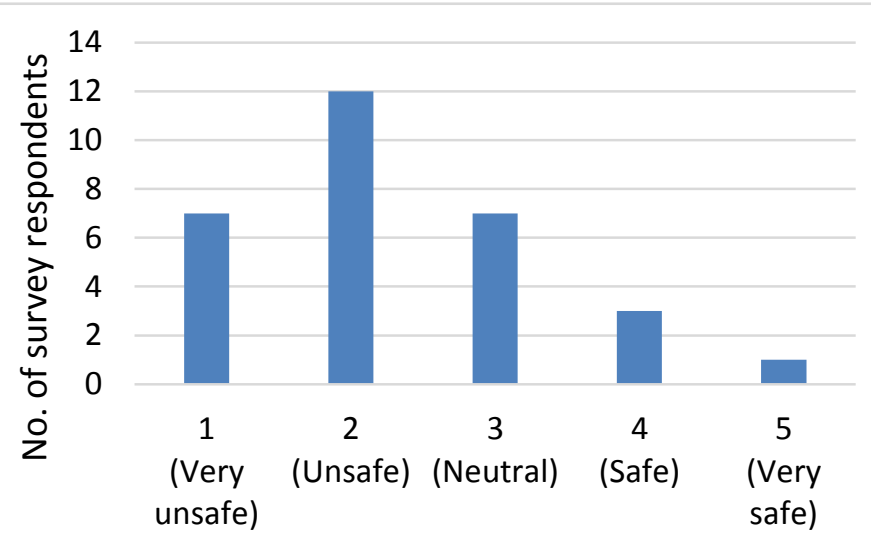




\subsubsection{Regulating buildings heights, colors, and materials}

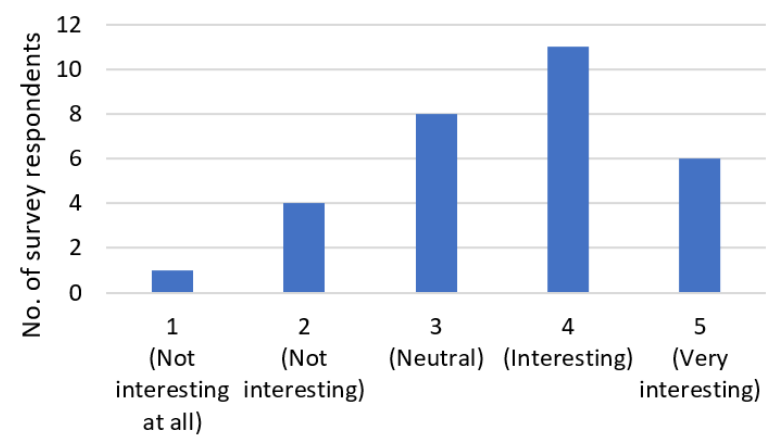

Figure 18. Participants response distribution to finding walking in Jamal Irfan street interesting.

\subsection{Recommendations for boosting walkability in Jamal Irfan street}

Despite of the physical and usability challenges, Jamal Irfan has some characters of walking friendly streets such as a great diversity in terms of uses and activities, attraction of different people, good economic opportunities (the shops have high rents in comparison to others in the city due to the street popularity), and night-life. The street has become a destination in itself and not just a drive through route. Accordingly, redeveloping Jamal Irfan as a pedestrian friendly street that has all the walkability criteria of protection, comfort, and enjoyment will attract more pedestrians and opportunities. The followings are some main recommendations for improving walkability in Jamal Irfan street.

\subsubsection{Regulating buildings setback and activating buildings frontage}

To achieve reinforce and define the street, it is essential to regulate the buildings setback in a way that the buildings follow a common line. This will help also with achieving continuity and enclosure, two key urban design principles. Projections and setbacks from the common building line in the street, such as bays and entrances for the businesses also add valuable emphasis "without undermining the principle of continuity" [32]. Activating the buildings frontage, especially in the ground floor level, is also important to enliven the street and intensify interaction between the pedestrians and the street elements.
It is also necessary to regulate the buildings heights to reduce the, relatively, high variations between buildings with only one and four floors to achieve a good quality continuity and continuous edge for the street. This will also help with regulating the street's skyline and street view. We recommend to have buildings with the same or close number of floors (three to four floors), in which the first floors are used for mixed-use activities. To create and emphasize the street identity and offer a good visual experience, we suggest regulating the building colors and materials. Contrast or harmony can be used a strategy for regulating materials and colors of the buildings as long as they create a pleasant visual experience for the pedestrians.

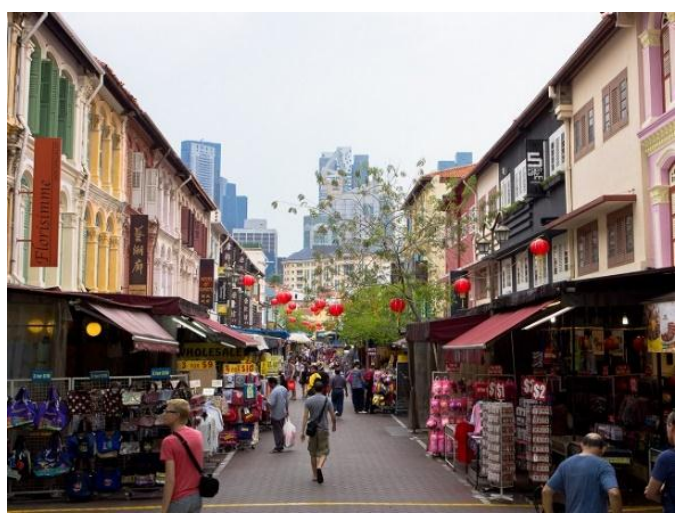

Figur

e 19.

An

examp

le of a vibrant street with activated buildings ground floor and strong continuity from regulated buildings setback and skyline.

\subsubsection{Adapting Complete Streets principles and elements}

To increase walkability in the street, we recommend adapting Complete Streets principles and elements. A complete street is one that is "designed and operated to enable safe access to all users, including pedestrians, bicyclists, motorists and transit riders of all ages and abilities" [33]. It makes street crossing, walking to shop, and bicycle to work safe and easy by providing adequate facilities and by reducing travel speeds in a way that all users and modes can use the street safely [34]. They support reliable public transportation. In a review of safety research by the Federal Highway Administration (FHWA) it was concluded that a variety of facilities and infrastructure commonly found in Complete Streets design (such as marked crosswalks, raised medians, pedestrian refuge islands, traffic control devices, careful bus stop placement, safe routes to school, traffic-calming 
measures, and continuous sidewalks and walkways) can serve as efficient countermeasures to pedestrian crashes [34].

A complete street may include: "sidewalks, bike lanes (or wide paved shoulders), special bus lanes, comfortable and accessible public transportation stops, frequent and safe crossing opportunities, median islands, accessible pedestrian signals, curb extensions, narrower travel lanes, roundabouts, and more" [33]. Currently, Jamal Irfan is far from being a complete street. To make it a complete street, many policies and designs have to be adopted for different elements of the street.

\subsubsection{Sidewalks}

In Complete Streets, sidewalks, which are central for pedestrians' movement, need to be re-designed according to international standards and anticipated pedestrian volumes. In general, the sidewalks need to include four main zones: frontage zone, pedestrian through zone, street furniture/curb zone, and enhancement/buffer zone. The frontage zone includes "the structure and façade of the buildings fronting the street and the space immediately adjacent to the buildings" [35]. The section works as an extension of the building since it can function as through entryways and doors and sidewalk cafes. The pedestrian through zone is the main, accessible pathway "that runs parallel to the street" [35]. This zone needs to provide pedestrian with safe and sufficient place to walk. In residential areas, its width should range from 1.5 to $3 \mathrm{~m}$ while in city center and commercial areas it must be wider ranging between 2 to 4 [35]. The street furniture zone is the section of the sidewalk between the pedestrian through zone and the curb zone, where the street furniture and amenities such as utility poles, lighting, tree pits, and benches are placed [35]. The enhancement/buffer zone refers to the space immediately adjacent to the sidewalk; It consist of a range of different elements such as curb extensions, parklets, parking, curbside bike lanes, or cycle tracks [35].

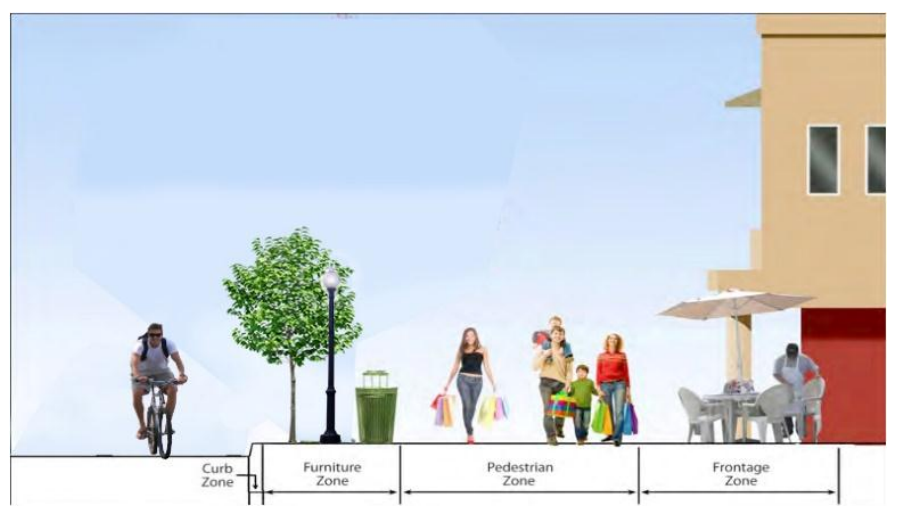

Figure 20. An illustration example of a sidewalk with the four zones.

The height and materials of the sidewalks should be designed and executed in a way that enable walking by people with different mobility levels, including disabled. This will make the street more welcoming and inclusive for pedestrians.

\subsubsection{Bike lanes}

In addition to increasing access to the street with different modes of transportation and offering more choice, adding bike lanes to the street will serve as a safety (real and perceived) buffer between the pedestrians' movement on the sidewalks and the vehicles on the street.

\subsubsection{Regulating traffics}

This can be done through providing adequate traffic and directional signs (including speed signs), marking crosswalks, and providing adequate car parking spaces (including street parking through curb extension in some areas), special bus lanes, comfortable and accessible public transportation stops, frequent and safe crossing opportunities, median islands, and accessible pedestrian signals.

\subsubsection{Providing reliable public transportation}

In addition to diversifying modes and choices of transportation, providing reliable public transportation in Jamal Irfan can increase access to the street. Additionally, it can reduce the use of private cars to access the street and, therefore, mitigate negative environmental impacts from car dependency.

\subsubsection{Increasing street furniture, greenery, and landscaping}

This includes providing adequate street lighting, benches, garbage bins, and good looking landscaping furniture and greenery. We recommend replacing overhead power providing system through utility poles (see Figure 16) with underground power providing system to remove the wires cluttering, which are negatively affecting the pedestrian's visual experience and, sometime, safety.

We also recommend planning tress with large enough canopy size. In addition to adding to the visual quality of the street and walking experience, the canopies provide much needed shade in the long hot summer season of the city for the protection and comfort of the pedestrians. 


\subsubsection{Promoting diversity}

Diversity is a key component for a walkable street. This can be done at different levels and scales. Diversifying types of shopping and activities for different customers and users will attract people from different age, gender, and background. Accommodating disabled people's needs and facilities is another strategy to diversify the users of the street.
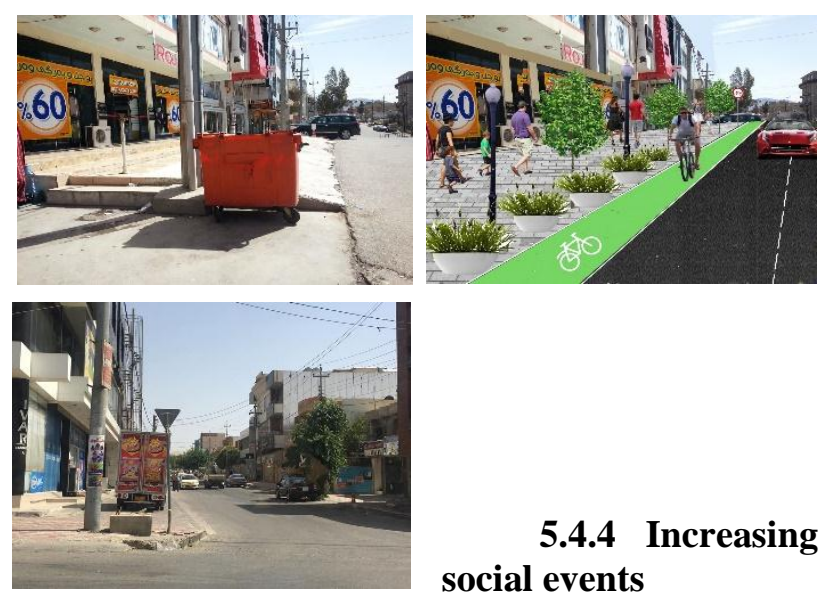

\subsubsection{Increasing \\ social events}

Given the street's proximity to some popular landmarks, we recommend arranging and increasing the number of social events and activities (including family-oriented) in the Youth center and park at the entrance to the street from Malik Mahmood street. In addition to enlivening the street life, such activities can further attract pedestrians to the street and increase social interaction and economic opportunities in the street.

Figure 21. Two photomontage scenarios of before and after redevelopment conditions in two sections of the street.

\section{CONCLUSIONS}

Walkability is an important asset for any street or space. It has numerous benefits and positive impacts. People in walkable environments live happier, healthier, and even wealthier. Walkable streets and environments do not happen accidentally; They require planning and considerations to principles like protection, comfort, and enjoyment. Despite the obvious benefits, cities like Sulaimani barely pedestrian friendly streets that are safe, comfort, and enjoyable simultaneously. The growing increase in number of mixed-use streets throughout the city are making walkability a priority for the city. In addition to increasing social interaction and economic opportunities, making the city's mixed-use streets more walkable ensure the pedestrians' safety, enjoyment, physical and mental well-being. To improve walkability in the city's mixed-use streets, this study examined a popular mixed-use street, Jamal Irfan, as a case study. Despite some physical and usability challenges discussed in the paper, the street has great potentials to become a safe and enjoyable walkable street. For this purpose, we made some recommendations that help with the street's transformation.

\section{REFERENCE}

[1] "Why walkability is important", Evds.ucalgary.ca, 2017. [Online]. Available: http://evds.ucalgary.ca/news/why-walkabilityimportant. [Accessed: 29- Aug- 2017].

[2] "Pedestrian Improvements", Vtpi.org, 2017. [Online]. Available: http://www.vtpi.org/tdm/tdm92.htm. [Accessed: 29Aug- 2017].

[3] D. Scopelliti, J. Hargrave, S. Claris and C. Luebkeman, "Cities alive", http://www.plataformaurbana.cl/, 2016. [Online]. Available: http://cdn.plataformaurbana.cl/wpcontent/uploads/2016/09/informe-arup-citiesalive.pdf. [Accessed: 29- Aug- 2017].

[4] D. Sinnett, K. Williams, K. Chatterjee and N. Cavill, "Making the case for investment in the walking environment: A review of the evidence", University of the West of England, Bristol, and Cavill Associates, London, 2011.

[5] D. Forkenbrock, S. Benshoff and G. Weisbrod, "Guidebook for assessing the social and economic effects of transportation projects", National Research Council, Iowa City, Iowa, 2001.

'A GIS based approach to measure neighborhood", MSc., University of rabad, India., 2008.

[7] T. Litman and S. Fitzroy, "Evaluating mobility management traffic safety impacts", Victoria Transport Policy Institute, 2017.

[8] J. Gilderbloom, W. Riggs and W. Meares, "Does walkability matter? An examination of walkability's impact on housing values, foreclosures and crime", Cities, vol. 42, pp. 13-24, 2015.

[9] "Developing a walking strategy", http://www.victoriawalks.org.au, 2013. [Online]. Available:

http://www.victoriawalks.org.au/Assets/Files/Final_ Guide_Walking_Strategies_WEB.pdf. [Accessed: 29- Aug- 2017].

[10] "A 15-minute daily walk 'will help you live longer' says study", nhs.uk, 2015. [Online]. Available:

http://www.nhs.uk/news/2015/08August/Pages/15minute-daily-walk-will-help-you-live-longer-saysstudy.aspx. [Accessed: 29- Aug- 2017]. 
[11] M. Melnick, "Just 15 Minutes of Exercise a Day May Add Years to Your Life", TIME.com, 2011. [Online]. Available: http://healthland.time.com/2011/08/16/just-15minutes-of-exercise-a-day-may-add-years-to-yourlife/. [Accessed: 29- Aug- 2017].

[12] D. Martínez-Gómez, J. Ruiz, S. GómezMartínez, P. Chillón, J. Rey-López, L. Díaz, R. Castillo, O. Veiga and A. Marcos, "Active Commuting to School and Cognitive Performance in Adolescents", Archives of Pediatrics \& Adolescent Medicine, vol. 165, no. 4, p. 300, 2011.

[13] C. Montgomery, "The secrets of the world's happiest cities", the Guardian, 2013. [Online]. Available:

https://www.theguardian.com/society/2013/nov/01/s ecrets-worlds-happiest-cities-commute-propertyprices. [Accessed: 29- Aug- 2017].

[14] A. Stutzer and B. Frey, "Stress that Doesn't Pay: The Commuting Paradox*", Scandinavian Journal of Economics, vol. 110, no. 2, pp. 339-366, 2008.

[15]"The economic benefits of walking", Victoriawalks.org.au, 2017. [Online]. Available: http://www.victoriawalks.org.au/economic_benefits/ . [Accessed: 29- Aug- 2017].

[16] M. Oppezzo and D. Schwartz, "Give your ideas some legs: The positive effect of walking on creative thinking.", Journal of Experimental Psychology: Learning, Memory, and Cognition, vol. 40, no. 4, pp. 1142-1152, 2014.

[17] "Why American companies are moving downtown", https://smartgrowthamerica.org, 2015. [Online]. Available: https://smartgrowthamerica.org/app/legacy/docume nts/core-values.pdf. [Accessed: 29- Aug- 2017].

[18] "Doing our bit: Cycling and walking", Sustainable-environment.org.uk, 2017. [Online]. Available: http://www.sustainableenvironment.org.uk/Doing_Our_Bit/Cycling_and_ Walking.php. [Accessed: 29- Aug- 2017].

[19] J. Speck, "The walkable city", Ted.com, 2013. [Online]. Available: https://www.ted.com/talks/jeff_speck_the_walkable _city. [Accessed: 29- Aug- 2017].

[20] "Quantifying Jeff Speck", Counting Pantographs, 2014. [Online]. Available: http://countingpantographs.org/2014/03/23/quantifyi ng-jeff-speck/. [Accessed: 29- Aug- 2017].
[21] L. Gemzøe, "Quality for people, a set of quality criteria for the design of pedestrian places and networks: With people in mind", in The 7th International Conference on Walking and Liveable Communities, Melbourne, Australia, 2006.

[22] S. Ng, C. Lai, P. Liao, M. Lao, W. Lau, S. Govada and W. Spruijt, "Measuring and Improving Walkability in Hong Kong", Civic Exchange and UDP International, 2016.

[23] "Making streets welcoming for walking", www.changelabsolutions.org, 2013. [Online]. Available:

http://www.changelabsolutions.org/sites/default/file s/Streets-Welcome-for-

Walking_FINAL_20131206_0.pdf;. [Accessed: 29Aug- 2017].

[24] X. Zhu and C. Lee, "Walkability and Safety Around Elementary Schools", American Journal of Preventive Medicine, vol. 34, no. 4, pp. 282-290, 2008.

[25] "Benefits of complete streets", www.smartgrowthamerica.org, 2009. [Online]. Available:

https://www.smartgrowthamerica.org/app/legacy/do cuments/cs/factsheets/cs-safety.pdf. [Accessed: 29Aug- 2017].

[26] M. Ernst and B. McCann, "Mean streets 2002", 2004.

[27] D. Rodriguez, "Active transportation: Making the link from transportation to physical activity and obesity", Active Living Research, San Diego, 2009.

[28] P. Hess, A. Moudon, M. Snyder and K. Stanilov, "Site Design and Pedestrian Travel", Transportation Research Record: Journal of the Transportation Research Board, vol. 1674, pp. 919, 1999.

[29] C. Addy, D. Wilson, K. Kirtland, B. Ainsworth, P. Sharpe and D. Kimsey, "Associations of Perceived Social and Physical Environmental Supports With Physical Activity and Walking Behavior", American Journal of Public Health, vol. 94, no. 3, pp. 440-443, 2004.

[30] "Relationship between speed and risk of fatal injury: Pedestrians and car occupants", https://nacto.org, 2010. [Online]. Available: https://nacto.org/docs/usdg/relationship_between_sp eed_risk_fatal_injury_pedestrians_and_car_occupan ts_richards.pdf. [Accessed: 29- Aug- 2017]. 
[31] "Creating safe park environments to enhance community wellness", Nrpa.org, 2017. [Online]. Available:

http://www.nrpa.org/contentassets/f768428a39aa40 35ae55b2aaff372617/park-safety.pdf;. [Accessed: 29- Aug- 2017].

[32] "Urban design in the planning SystemTowards better practice", www.designcouncil.org.uk, 2000. [Online]. Available:

http://www.designcouncil.org.uk/sites/default/files/a sset/document/by-design_0.pdf. [Accessed: 29Aug- 2017].

[33] "What are Complete Streets?", Smart Growth America, 2017. [Online]. Available: https:/smartgrowthamerica.org/program/nationalcomplete-streets-coalition/what-are-completestreets/. [Accessed: 29- Aug- 2017].

[34] "Benefits of Complete Streets", NJ Bicycle and Pedestrian Resource Center, 2017. [Online]. Available: http://njbikeped.org/services/benefits-ofcomplete-streets/. [Accessed: 29- Aug- 2017].

[35] "Urban street design guide", National Association of City Transportation Officials, 2017. [Online]. Available: https://nacto.org/publication/urban-street-designguide/street-design-elements/sidewalks/. [Accessed: 29- Aug- 2017].

\section{Biography}

Mariwan Jamal, Wanawsha Khasraw, and Shaey Khabat are graduating students from the City Planning Engineering Department, Technical College of Engineering, Sulaimani Polytechnic University.

Dr. Rozhen Kamal Mohammed-Amin is an academic, architect, urban designer and planner, and a writer. She is a lecturer at the City Planning Engineering Department and a Research Center Coordinator at the Sulaimani Polytechnic University. She has an interdisciplinary background and experience. She earned her BSc. in Architectural Engineering from University of Sulaimani and Master's and $\mathrm{PhD}$ degrees from the University of Calgary in Canada. She brings professional, academic, and international experiences to her practices, teachings, and scholarly works. As an architect, she has designed, co-designed, and supervised numerous architectural projects, including residential, commercial, office, and recreational buildings. As an urban designer and planner and designer, she has been involved in developing and supervising the development of several master plans in both then State Organization of Tourism (SOT) and the Directorate of Urban Planning and Design at the Ministry of Municipality and Tourism (MOMT). She is actively involved in researching and scholarly activities both nationally and internationally. Dr. Mohammed-Amin publishes her research at national and international conferences and gets invited to speak and lecture in North America, UK, Europe, Asia, Gulf counties, and Iraq. 